\title{
Calidad de la democracia en gobiernos locales: problemas y perspectivas en México
}

Introducción

Desde sus inicios, el estudio de la calidad de democracia se ha enfocado mayoritariamente en naciones enteras y son escasas las ocasiones en que se ha abordado el caso de los gobiernos locales. El presente trabajo busca hacer frente a tal

El estudio de la calidad de democracia se ha enfocado mayoritariamente en naciones enteras, tratando solo en escasas ocasiones a los gobiernos locales. En el presente trabajo se describen algunos de los problemas y perspectivas que conlleva

realizar estudios sobre la calidad de la democracia en el ámbito subnacional. El trabajo pretende poner en discusión, a través de los inconvenientes que plantea el caso mexicano, la problemática teórica, conceptual, metodológica y contextual para el estudio de la calidad de la democracia en los gobiernos locales. Lo anterior con el fin de impulsar una agenda de investigación que busque resolver tales inconvenientes, aspire

a construir evidencia confiable y permita obtener mejores explicaciones.

Palabras clave: calidad de la democracia, gobiernos locales, problemas, perspectivas,

México.

- Investigador de tiempo completo de El Colegio de San Luis, A.C.

hborjas@colsan.edu.mx desatención al exponer algunos de los problemas y perspectivas que conlleva realizar estudios sobre la calidad de la democracia en el ámbito sub-nacional.

El trabajo pretende poner en discusión, a través de los inconvenientes que plantea el caso mexicano, la problemática teórica, conceptual, metodológica y contextual para el estudio de la calidad de la democracia. Lo anterior a fin de impulsar una agenda de investigación que busque resolver tales inconvenientes, aspire a construir evidencia confiable y permita obtener mejores explicaciones.

En esta lógica, el trabajo muestra en un inicio algunos apuntes previos para el caso mexicano con el objeto de dar cuenta de la particularidad de la transición mexicana, evento que impacta directamente en la 
evaluación de la calidad de su democracia y que, sin duda alguna, trasciende a los gobiernos estatales y municipales.

Posteriormente, se presentan los problemas para medir la calidad de la democracia en gobiernos locales, para los cuales se establecen tres tipos: a) problemas teóricos, b) problemas conceptuales y metodológicos, y c) problemas contextuales.

Los problemas teóricos presentan la problemática que nace de los grandes trabajos de los estudios sobre la calidad de la democracia y la dificultad que conlleva su aplicación más próxima al estudio de los gobiernos locales. En los problemas conceptuales y metodológicos se sigue la línea de los problemas teóricos, en el sentido de cómo resolver problemas que aún no tienen solución en los estudios de la calidad de la democracia en países enteros, reconociendo que el ámbito local incrementa la complejidad. Finalmente, se exponen las consideraciones a los problemas contextuales para la medición de la calidad de la democracia en los gobiernos locales. Para ello se consideran tres: baja institucionalización, acrecentamiento del poder de las autoridades locales y resurgimiento y fortalecimiento de poderes fácticos locales.

Las conclusiones retoman estas problemáticas teóricas, conceptuales, metodológicas y contextuales que enfrentan los estudios de la calidad de la democracia en los gobiernos locales y plantean nuevas perspectivas y consideraciones a tener en cuenta por parte de las investigaciones a venir.

\section{Apuntes previos para el caso mexicano}

Para el caso mexicano es importante destacar el tipo de transición, o mejor dicho la forma atípica de su transición, toda vez que no ha sido una transición que se acomode a los tipos que se han presentado en otras naciones. Asimismo, para el caso de México habría que hacer valer las observaciones de Morlino (2007) sobre la importancia que guardan las 
Calidad de la democracia en gobiernos locales: problemas y perspectivas en México

tradiciones autoritarias heredadas para explicar la calidad de la democracia.

Así pues, un desacuerdo inicial sobre la transición en México es el de su duración, pues bien a bien no hay claridad de que esta haya siquiera concluido. ${ }^{1}$ Según la caracterización de Whitehead (1996), la transición en México llegó por vía de la alternancia, en este caso por el arribo del Partido Acción Nacional (PAN) al ejecutivo federal en el año 2000. Sin embargo esta transición por "alternancia" no construyó cambios fundamentales a partir de que el PAN se encontrara en la presidencia de la República. Es decir, la época en donde el partido hegemónico, el Revolucionario Institucional (PRI), gobernó sin cortapisa y estableció un sinnúmero de reglas no escritas ${ }^{2}$ no ha quedado del todo atrás. El PAN no demostró otra forma de gobernar ni consolidó los cambios institucionales y constitucionales profundos, mientras que sí se valió de algunas viejas pautas heredadas de su antecesor en el poder. Con lo cual, se puede decir que durante el largo periodo que se le suele atribuir a la transición en México -a decir un cuarto de siglo según Cansino y Covarrubias (2007) - no existió un pacto de las élites, no hubo ruptura o caída del régimen y la alternancia en el poder que se dio no parece que haya cambiado las condiciones ni haya terminado de instaurar un nuevo orden institucional.

Por supuesto que sí se presentaron cambios, pero estos no se le pueden atribuir únicamente a la alternancia, ya que fueron cambios que ocurrieron paulatinamente a lo largo del periodo de transición que se reconoce. Cambios tales como alcaldes de partido diferente al del gobernador, congresos con diputados de muy distinto color, alternancias en las

I. Aquí se acoge lo que Morlino entiende por transición: "el período ambiguo e intermedio en que el régimen ha abandonado algunos caracteres determinantes del ordenamiento institucional anterior sin haber adquirido todos los caracteres del nuevo régimen que será instaurado" (Morlino, 2005b, p. 146).

2. Véase a Hurtado (200I, p. 299).

Estado 8 No. 62 
presidencias municipales repitiéndose con naturalidad, inexistencia de ganadores y perdedores predeterminados, gobiernos divididos en el ámbito federal y estatal, entre otros (Woldenberg, 2006, p. 17).

Estos cambios pertenecen mejor dicho a aquello que se ha hecho llamar liberalización política, y por lo tanto no se derivan directamente de la voluntad de la élite gobernante, sino que han sido producto de pequeñas concesiones de esta élite para sostenerse en el poder. Dicho de otra manera, tal parece ser que los cambios y la atípica transición mexicana son producto de una inercia en donde la fuerza que la ha movido no tiene nombre propio ni se le puede adjudicar a nadie en particular. ${ }^{3}$ Tan es así que como dicen Cansino y Covarrubias (2007, p. 21): "México se encuentra después de la transición en una suerte de limbo, en el que los valores y las prácticas democráticas surgidas de la transición no pueden ser albergadas de manera virtuosa en el entramado institucional y normativo vigente, que no es otro que el heredado del viejo régimen".

Aún más, lo anómalo de la transición mexicana se remonta a sus inicios, pues como afirma Morlino (2005b, p. 147), la transición suele iniciarse con el reconocimiento de los derechos civiles y sociales, y en seguida, de los derechos políticos, cuando en el caso mexicano ocurrió de manera inversa: se reconocieron primero los derechos políticos antes que los civiles y sociales (Woldenberg, 2006, p. 22). Así pues, la complejidad de la transición mexicana encuentra su base en el desarrollo diferenciado que presentan los derechos 
Calidad de la democracia en gobiernos locales: problemas y perspectivas en México

políticos, ${ }^{4}$ civiles $^{5}$ y sociales ${ }^{6}$ en el ámbito nacional frente a los ámbitos locales. Un error común por parte de numerosas investigaciones es adjudicar aseveraciones que derivan del ámbito nacional a lo que acontece con la democracia en ámbitos subnacionales, dando lugar a explicaciones que no se corresponden en nada con la realidad local.

A lo dicho conviene añadir que mientras que en el gobierno federal la alternancia se da en el año 2000, esta ya se había dado décadas atrás en algunas alcaldías y gubernaturas de los estados. ${ }^{7}$ Tales divergencias también ocurren con otras formas políticas, como la segunda vuelta, la presencia de gobiernos divididos y algunas otras; ${ }^{8}$ todo lo cual nos dice que la transición mexicana ha corrido en varias pistas que no llevan el mismo ritmo, siendo estas la federal, por un lado, y las estatales y municipales, por el otro. Producto de

4. "Los derechos políticos incluyen el derecho al voto, el derecho a que los líderes políticos puedan competir por el apoyo electoral y el derecho a ser electo para un cargo público (electorado pasivo)" (Morlino, 2005a, p. 47).

5. "Los derechos civiles esenciales incluyen la libertad personal, el derecho a una defensa legal, el derecho a la privacidad, la libertad de elegir el lugar de residencia, la libertad de movimiento, el derecho a emigrar, la libertad y el secreto de correspondencia, la libertad de pensamiento y expresión, el derecho a la información y una prensa libre, y la libertad de asamblea, asociación y organización, incluyendo organizaciones políticas sin vínculo alguno con los sindicatos" (Morlino, 2005a, p. 47).

6. Morlino (2005a, p. 48) entiende por derechos sociales en una democracia "el derecho a la salud o al bienestar físico y mental, el derecho a la asistencia y la seguridad social, el derecho al trabajo, el derecho a la dignidad humana, el derecho a la huelga, el derecho al estudio y la educación, así como el derecho a entornos saludables, concretamente, a la protección del ambiente, y el derecho a la vivienda". 7. El primer municipio ganado por la oposición fue el de Quiroga, Michoacán, por Manuel Torres Serranía en 1947 y el primer estado ganado por la oposición fue el de Baja California por Ernesto Ruffo Appel en 1989.

8. El primer y único estado que ha instaurado la segunda vuelta es San Luis Potosí en la Ley Electoral del Estado de 1996; posteriormente se derogó en las reformas efectuadas con fecha 30 de julio de 2005 a la Ley Electoral de septiembre de 1999 En el ámbito federal, en México, el fenómeno de los gobiernos divididos o de los gobiernos sin mayoría se presenta, estrictamente, hasta 1997,y en las experiencias locales se fue gestando y produciendo desde 1989, con la aparición paulatina de gobiernos divididos principalmente en los estados de Baja California, Guanajuato, Baja California Sur, Chihuahua,Aguascalientes, México, Coahuila, Morelos, Colima, Querétaro, Sonora y Jalisco. 
estas diferencias es que hoy se bifurcan las expectativas democráticas del ámbito federal respecto de los ámbitos locales, ya que se están presentando fenómenos dispares.

De tal suerte que el estudio de la calidad de la democracia en los gobiernos locales ha de considerar seriamente la presencia de estos fenómenos. Quizá México sea el país de América Latina que presenta de forma más acusada estas características, pero esto no significa que se trate de un caso aislado. En lo general, los países latinoamericanos no se caracterizan por el reconocimiento uniforme en todas sus regiones de derechos sociales, civiles y políticos.

\section{Problemas para medir la calidad de la democracia en gobiernos locales}

Existe hoy en día un amplio reconocimiento de la difícil tarea de establecer una medida universal para la calidad de la democracia, así como de las diferencias existentes entre los diversos tipos para evaluarla y sus consecuentes problemas. ${ }^{9}$ Ante este escenario, es pertinente establecer parámetros generales que puedan ser observados y teorizados en cualquier ámbito local a partir de lo que la literatura sobre calidad de la democracia ya ha señalado. Queda claro que los gobiernos locales tienen sus propios problemas al estudiarlos bajo la óptica de la calidad de la democracia, pero además son herederos de los problemas teóricos, conceptuales y metodológicos ya existentes en la literatura sobre la calidad de la democracia a nivel nacional.

9. Véase Altman y Pérez-Liñan (2002) para las diversas medidas para evaluar la calidad de la democracia, a Levine, Daniel y José Enrique Molina (2007) para algunos problemas y alternativas existentes en la medición y Alcántara (2008) para las diferencias que se presentan en estas medidas. 
Calidad de la democracia en gobiernos locales: problemas y perspectivas en México

\section{Problemas teóricos}

Al hilo de lo anterior, conviene reconocer que los avances que se tienen respecto de la calidad de la democracia son considerables. No obstante, para el estudio de la calidad de la democracia en los gobiernos locales hay que dar pasos hacia atrás, toda vez que, como ya se ha señalado más arriba, el avance de la democracia en el ámbito nacional difiere del ámbito subnacional. Y a esta consideración no escapa la literatura existente sobre la calidad de la democracia, pues los progresos que se tienen están enfocados a países enteros y no a unidades subestatales. De ahí que resulta más pertinente partir de lo que la literatura en cuestión considera más firme y no intentar forzar la teoría y los hallazgos en los estudios de los gobiernos locales.

Este hecho abre por sí mismo una discusión respecto a los avances que se han dado en la teoría existente sobre la calidad de la democracia, y si algo ha caracterizado a la literatura sobre el tema es justamente el debate. No obstante, existe un piso mínimo a partir del cual se ha movido la teoría en los últimos años. En este sentido, los trabajos destacados buscan en primera instancia aclarar la idea de democracia y de ahí construir lo que se ha de entender por calidad de la democracia. Al respecto Schmitter (2007) hace anotaciones más que pertinentes que se pueden considerar válidas para los gobiernos locales, pues anuncia que la discusión sobre la calidad de la democracia ha sufrido muchas falacias entre las que apunta: el anacronismo, el idealismo y el partidismo. El anacronismo se entiende como el error en la medición que ha sido producto de un desfase en los tiempos de la evolución de la democracia; esto es, el mirar a las neodemocracias con estándares demasiado elevados cuando su propia evolución no les permite aún contar con ellos. La segunda falacia, el idealismo, se refiere a que la democracia es una aspiración que en estricto sentido ningún país ha alcanzado. Y por último, el partidismo, refiriéndose 
al hecho de que la medición de la democracia se hace con base en las consideraciones del que la mide; es decir, de acuerdo a los criterios que el investigador considera que se han de tener en una democracia (Schmitter, 2007).

Pues bien, el anacronismo, el idealismo y el partidismo son falacias que atañen también a los gobiernos locales, pues como ya se decía, es común que se les exijan estándares del ámbito nacional que la propia evolución democrática local no les permite alcanzar aún; sabedores de que su ritmo de evolución es otro. Ni mejor ni peor, sino otro. De aquí el énfasis en señalar que la teoría de la calidad de la democracia que hoy se tiene debe tratarse con sumo cuidado en su extrapolación a los gobiernos locales.

Por todo esto, y con el afán de establecer un marco común de referencia para el estudio de la calidad de la democracia en gobiernos locales, una pauta inicial a considerar es la dada por Morlino (2005a) a partir del reconocimiento de tres dimensiones: el gobierno de la ley o Estado de derecho (rule of law), ${ }^{10}$ la rendición de cuentas (accountability) ${ }^{11}$ y la reciprocidad (responsiveness). ${ }^{12}$ Esta última haciendo valer la sugerencia de Morlino (2005a) de tratarla en conexión con la rendición de cuentas; motivo que impulsa su inclusión en el presente trabajo. Aunque coincidimos plenamente con

\footnotetext{
10. Según Maravall (2003, p. 170):"[...] consiste en el cumplimiento de leyes que (I) se han promulgado de manera pública y se han aprobado de una forma establecida de antemano; (II) son prospectivas (nulla poena sine lege), generales (casos similares se tratan de forma parecida), estables, claras y ordenadas jerárquicamente (las normas más particulares acatan las más generales); (III) las aplican a los casos individuales unos tribunales independientes de los gobernantes $y$ abiertos a todo el mundo, cuyas decisiones responden a requisitos procedimentales, $y$ que determinan la culpabilidad mediante un proceso jurídico ordinario".

II. De acuerdo con Schedler (2004, p. 12):“[...] tiene dos dimensiones básicas. Incluye, por un lado, la obligación de políticos y funcionarios de informar sobre sus decisiones y de justificarlas en público (answerability). Por otro, incluye la capacidad de sancionar a políticos y funcionarios en caso de que hayan violado sus deberes públicos (enforcement)".

12. Siguiendo a Morlino (2005a: 44): “[...] capacidad de satisfacer los intereses de los gobernados al ejecutar las políticas que responden a sus demandas”.
} 
Calidad de la democracia en gobiernos locales: problemas y perspectivas en México

las dudas de Powell (2007) para encontrar medidas de la reciprocidad que ayuden a evaluar sin dificultad su calidad en sistemas democráticos. Dos dimensiones más -libertad e igualdad-no se habrán de considerar aquí, toda vez que, al menos en el caso mexicano, no alcanzan un desarrollo sustancial y uniforme en los gobiernos locales; siendo éste uno de los problemas principales para la medición de la calidad de la democracia. ${ }^{13}$

Pues bien, el considerar solo al Estado de derecho, a la rendición de cuentas y a la reciprocidad, esta última en mucha menor medida por los problemas que representa determinar su calidad, como únicas dimensiones aplicables a los gobiernos locales, se podría interpretar como un enfoque reduccionista para lo que la teoría ofrece. Sin embargo, es preferible iniciar con un desarrollo modesto en los estudios empíricos de los gobiernos locales que enfrentarse a lo que ocurre con los estudios de naciones enteras, en donde el desarrollo teórico de la calidad de la democracia y sus dimensiones van muy por delante de la investigación empírica. Hecho que a la postre redunda en pasos hacia atrás en los esfuerzos teóricos. La investigación empírica sobre la calidad de la democracia se ha transformado en un ejercicio típico de prueba y error en donde la discusión, en cualquiera de sus aspectos, parece que va y viene. ${ }^{14}$ No mucho más de lo que nace de estas tres dimensiones se puede incorporar al estudio de la calidad de la democracia en gobiernos locales, en donde incluso la dimensión referida a la reciprocidad, como ya se mencionó, presenta fuertes amenazas a su concreción.

Como se podrá observar, al estudiar la calidad de la democracia en los gobiernos locales se debe tener sumo cuidado

13. Se hizo referencia a este hecho dentro de las anomalías de la transición mexicana cuando se manifestó que en México primero se reconocieron los derechos políticos antes que los civiles y sociales. I4.Véase Schmmiter (2007). 
en la utilización de la teoría existente y conviene, en este caso, buscar contribuir y precisar a la misma, sin asumir por entero su aplicación en este ámbito. Observaciones a este punto se abordan en el apartado siguiente.

\section{Problemas conceptuales y metodológicos}

Los problemas conceptuales y metodológicos descritos por Munck y Verkuilen (2002) siguen siendo un lastre para el análisis de la democracia y estos problemas han sido transmitidos para el estudio de su calidad. Si bien aquí no se pretende reescribir aquel trabajo, sí se busca enfatizarlo y dar cuenta de que no se han superado los escollos de entonces.

\section{Conceptos y traducciones}

Uno de los problemas iniciales que se tienen en la literatura sobre la calidad de la democracia es su conceptualización, la cual se ve alterada aún más cuando se lleva a cabo el trabajo de traducción de los conceptos. Es importante destacar que la mayoría de la literatura circulante sobre la calidad de la democracia está en inglés y que su paso al español no siempre es terso ni siempre lo realizan especialistas en el tema.

El ejemplo favorable lo tenemos con el término accountability (rendición de cuentas). Gracias a que un especialista como Andreas Schedler (1999) abordó el problema de forma ejemplar y temprana para su entendimiento en ambas lenguas, hoy no se discute el concepto y sus atributos ${ }^{15}$. Sin embargo no ha ocurrido así con la dimensión rule of law (gobierno de la ley o Estado de derecho) ni con responsiveness (reciprocidad). Y ni qué decir ya de sus propios atribu-

15. Se está haciendo referencia al trabajo "Conceptualizing Accountability", publicado en The Selft-Restraining State: Power and Accountability In New Democracies de A. Schedler, L. Diamond y M. F. Plattner (eds.), que posteriormente reescribió en español y se publicó en 2004 en México por el Instituto Federal de Acceso a la Información Pública bajo el título Qué es la rendición de cuentas. 
Calidad de la democracia en gobiernos locales: problemas y perspectivas en México

tos, medición e indicadores. Claramente se están tomando las tres dimensiones por ser las de reconocimiento más amplio y por restarle así complejidad, pues el considerar más dimensiones como lo hacen otros trabajos (Diamond et al., 2004; Morlino, 2005a; Levine et al., 2007; Emmerich, $2009)^{16}$ complicaría las observaciones y nos haría caer en las mismas trampas que los estudios sobre la calidad de la democracia en naciones enteras han caído. Esto es, en parte, lo que Schmitter señalaba cuando hablaba de "partidismo" al mencionar que los observadores suelen ver la calidad de la democracia a través de lo que a ellos les gustaría que hiciera su partido de referencia (Schmitter, 2007, p. 85-6). De modo que para no entrar en una discusión que no se ha resuelto aún, respecto de cuáles son las mejores dimensiones para medir la calidad de la democracia, nos detenemos en las tres mencionadas que ya por sí mismas tienen su problemática.

Decíamos entonces que las dimensiones de gobierno de la ley y reciprocidad han sido traducidas al español y en el tránsito se han tenido que incorporar atributos a dichos conceptos que no todos asumen que así sea. Esto en sí mismo representa un problema, pues como decían Munck y Verkuilen (2002, p. 407), el significado del concepto "afecta a todo el proceso de generación de datos, pues es el punto de referencia de todas las decisiones siguientes". Y se hace patente en mayor grado cuando se tratan los gobiernos locales, ya que en no pocas ocasiones los conceptos tienen o exigen demasiado para lo que la realidad presenta.

16. No se ignora que el propio Morlino sugiere dos más: libertad e igualdad (Morlino, 2005a) y que en el trabajo con Diamond la rendición de cuentas se divide en vertical y horizontal, además de incorporar las dimensiones de participación y competencia (Diamond et al., 2004). Asimismo, otros trabajos como el de Levine et al. (2007) se ajustan al de Morlino, pero con ligeros cambios en donde incorporan las dimensiones decisión electoral, participación y soberanía. Para el caso mexicano en una evaluación de la democracia hecha por Emmerich (2009), quien se basa en cuatro dimensiones: a) ciudadanía, leyes y derechos, b) representación y responsabilidad gubernamental, c) sociedad civil y participación popular, y d) la democracia más allá de las fronteras del Estado.

Estado 8 No. 62 
En resumen, los estudiosos de los gobiernos locales han de prestar especial atención al tratamiento de los conceptos y sus traducciones y cuidarse de no incorporar demasiados atributos a fin de no crear conceptos maximalistas. Por el contrario, es preferible ser parsimoniosos, como recomienda Sartori (1984), sin llegar a contar con conceptos minimalistas en donde se pueda interpretar que cabe todo. ${ }^{17}$

\section{Índices y metodologías}

Si bien los problemas que se presentan en esta línea ya han sido abordados ampliamente en la literatura, no está demás hacer hincapié en ellos, ya que la problemática se incrementa cuando lo que se quiere estudiar son los gobiernos locales. Ya Munck y Verkuilen (2002) hicieron espléndidas observaciones a nueve índices sobre la democracia, ${ }^{18}$ encontrando deficiencias importantes en todos ellos. Años más tarde Levine y Molina (2007) desarrollaron un índice apoyándose en diversos índices previamente elaborados. Y más recientemente Alcántara (2008) realizó una descripción de otros cuatro índices de la democracia ${ }^{19}$ encontrando también diferencias importantes entre ellos. Así pues, trabajos como estos dan cuenta de la poca atención que se suele poner a la metodología con que está construido cada índice; lo cual pone en evidencia que lo único que interesa en la mayoría de los casos son solo los resultados; dejando de lado la calidad y fiabilidad del índice en cuestión.

No obstante, hemos de distanciarnos de la afirmación que hacen Munck y Varkuilen (2007, p. 437), quienes creen que "tener una base de datos sobre democracia, por defectuoso

17.Véase Munck y Verkuilen (2002).

18. I) Álvarez, Cheibub, Limongi y Pzeworski; 2) Arat; 3) Bollen; 4) Coppedge y Reinicke; 5) Freedom House; 6) Gasiorowski; 7) Hadenius; 8) Polity IV (Marshal y Jaggers); y 9) Vanhanen. Para más información véase Munck y Verkuilen (2002). 19. I) Freedom Huouse, 2) IDD (Fundación Konrad Adenauer), 3) The Economist Intelligence Unit (EIU); y 4) Levine y Molina. Para más información véase Alcántara (2008). 
Calidad de la democracia en gobiernos locales: problemas y perspectivas en México

que sea, es mejor que no tener ninguno y que los estudiosos deben usar lo que tienen a disposición”. Este razonamiento resulta particularmente dañino para los estudios de los gobiernos locales, puesto que las bases de datos, cuando las hay, son deficientes o fácilmente manipulables, por lo que no podemos pensar que esto es mejor que no tenerlas.

En síntesis, la idea central de este apartado busca llamar la atención a los estudiosos de los gobiernos locales para iniciar la construcción de bases de datos con los conceptos, atributos, mediciones, indicadores y metodologías adecuadas para cada caso; y de ser posible, uniformes. En la actualidad, la utilización de muchos y muy diversos índices ${ }^{20}$ ha tenido por consecuencia la extracción de evidencia débil que necesita demasiada explicación para volverse correcta.

En concordancia con lo dicho, y reconociendo la importancia que los estudios cuantitativos pueden llegar a tener a futuro en los estudios de calidad de la democracia a nivel local, es pertinente señalar que debido a la precariedad de la información y la baja fiabilidad de los datos disponibles por ahora, es preciso ser cautos al momento formular explicaciones, puesto que cuando se pretende encontrar respuestas a lo que ocurre en la realidad local, surge un aspecto que con frecuencia se impone y es el contexto; es decir, el contexto ha de ser de observancia obligatoria al estudiar los gobiernos locales, transformando los estudios cuantitativos -que suelen ser mayoría en el caso de la calidad de la democracia-, en mixtos, dada la necesidad de incorporar en ellos la interpretación cualitativa.

20. Por mencionar algunos para el caso de América Latina tenemos a Freedom Huouse, Latinobarómetro, IDD (Fundación Konrad Adenauer),The Economist Intelligence Unit (EIU), Levine y Molina, Transparency International, World Value Survey.

Estado 8 No. 62 


\section{Problemas contextuales}

Estos son quizás los problemas más importantes para la medición de la calidad de la democracia en gobiernos locales, porque mientras que los problemas teóricos, conceptuales y metodológicos se encuentran ya en discusión, al menos a nivel nacional, los problemas de los contextos locales reciben menor atención y por ende experimentan un menor avance.

Una realidad evidente es que los gobiernos locales no son la reproducción de lo que ocurre en el ámbito nacional, y este ha sido un error en el que con frecuencia se incurre: establecer explicaciones de lo que ocurre en los gobiernos locales a partir de la evidencia extraída de la nación entera. En el caso mexicano, y con toda seguridad en muchos países de América Latina, los gobiernos locales tienen vida propia y responden a inercias locales. ${ }^{21}$

En consecuencia, tomando como referencia el caso mexicano, se pueden reconocer tres problemas que afectan a la calidad de la democracia en los gobiernos locales: la baja institucionalización, el acrecentamiento del poder de las autoridades locales, y el resurgimiento y fortalecimiento de poderes fácticos locales.

\section{Baja institucionalización}

La baja institucionalización en América Latina es un fenómeno que ha sido ampliamente documentado (Alcántara, 2008) y México no escapa de esta rotulación. A casi quince años de ocurrida la alternancia y de la caída del partido hegemónico, las instituciones no son más fuertes. Esta transición mexicana sui generis no ha producido cambios normativos que redunde en mejores instituciones. A lo sumo, lo que se ha presentado son instituciones de gran valía que se han creado en este periodo. Tal es el caso de los organismos de transparencia y rendición de cuentas, 
Calidad de la democracia en gobiernos locales: problemas y perspectivas en México

los cuales, a contracorriente de lo que se sugiere (Morlino, 2005a), nacen en el ámbito federal para poco a poco ir reproduciéndose en los gobiernos locales. ${ }^{22}$ Por otra parte, las instituciones encargadas de la defensa de los derechos humanos tienen mayor presencia; no obstante, y por haber sido un proceso vertical que fue de arriba hacia abajo, en los gobiernos locales no se tiene la fuerza suficiente para hacerse valer. En resumen, se pueda afirmar que la democracia procedimental cumple con todos sus atributos, pero la democracia sustantiva deja mucho que desear. Dicho más claramente, las instituciones están ahí, pero los ciudadanos todavía no las reconocen. Además, los hombres al frente de estas instituciones hasta no hace mucho tiempo desconocían sus tareas; motivo por el cual muchas de ellas experimentaron un funcionamiento muy precario en sus primeros años y algunas otras continúan igual.

No ha ocurrido así con las instituciones electorales, que podrían considerarse la excepción. Es más que sabido que la democracia mexicana ha sido una democracia electoral y que durante algún tiempo la institución federal de mayor prestigio fue justamente la autoridad electoral. Esta inercia fue compartida por los gobiernos locales. De tal suerte que dentro de las instituciones del Estado, y pese a los vaivenes políticos producto de elecciones competitivas, desaciertos y problemas varios, los organismos electorales mantienen una cierta fortaleza en los gobiernos locales. Pero insistimos, es la excepción.

22. El Instituto Federal de Acceso a la Información se crea en 2002 y en los gobiernos locales se van creando como se muestra: en el año 2002, Jalisco, Sinaloa, Aguascalientes, Michoacán, Querétaro; en el año 2003, Nuevo León, Durango, Colima, San Luis Potosí, Distrito Federal, Guanajuato, Morelos, Coahuila; en el año 2004, el Edo. de México, Quintana Roo,Yucatán,Veracruz, Nayarit, Zacatecas, Tlaxcala, Puebla, Tamaulipas; en el año 2005, Sonora, Baja California Sur, Campeche, Baja California, Guerrero, Chihuahua; en el año 2006, Oaxaca, Chiapas, Hidalgo; y en el año 2007, Tabasco.

Estado 8 No. 62 
En consecuencia, la baja institucionalización y la ausencia de una reglamentación que cambie la inercia y fortalezca las instituciones han permitido que sobrevivan y se afiancen prácticas informales añejas, lo cual hace aún más difícil la construcción de evidencia empírica. Este hecho afecta directamente a dos dimensiones que nos interesan sobre la calidad de la democracia: el Estado de derecho y la rendición de cuentas.

En México, el Estado de derecho o gobierno de la ley en los gobiernos locales presenta características especiales, en dónde grandes prácticas informales modifican cualquier índice que se pretenda establecer. Basta considerar aquellos municipios que se rigen por usos y costumbres para dar al traste con cualquier noción de gobierno de la ley. ${ }^{23}$ Pese a ello, no se puede afirmar que los gobiernos locales sean lugares sin ley. Ya lo afirmaba O'Donnell (1999) cuando se refiere a las "áreas marrones" que se encuentran fuera de las grandes ciudades en las neodemocracias americanas. También lo suscribe Schmitter (2007) al reconocer que efectivamente hay lugares en los cuales hay una aceptación divergente entre las implicaciones de un gobierno de la ley y las implicaciones de un ejercicio democrático; esto es, lugares en donde el gobierno de la ley ha tenido respuestas y progresos, más no así las prácticas democráticas.

Finalmente, la rendición de cuentas en los gobiernos locales tiene una reproducción -a la fecha vigente- de lo que O’Donnell (1997) apuntaba para las nuevas poliarquías hace una década y media. Esto es un rechazo a la rendición de cuentas horizontal por parte de las autoridades encargadas de llevarla a cabo; son ellas quienes se sienten con derecho a hacer y deshacer únicamente por haber sido votadas en elecciones legalmente establecidas. Y de nueva cuenta tene-

23. El caso más excesivo en México lo representa Oaxaca, el cual cuenta con 570 municipios de los 2438 existentes en el país y de ellos $418(17,14 \%)$ se rigen por usos y costumbres. 
Calidad de la democracia en gobiernos locales: problemas y perspectivas en México

mos lo que O’Donnell (1994) apuntaba como "democracias delegativas", es decir, la persona que gana las elecciones se siente autorizada para gobernar como considera conveniente, limitado solo por las relaciones de poder existentes y el término de su mandato (O’Donnell, 1994, p. 60). Lo anterior, por supuesto, atenta contra las instituciones y la institucionalidad, asimismo abona al resguardo de una baja institucionalización.

Todo lo descrito hasta aquí complica la medición de la calidad de la democracia en los gobiernos locales, ya que estos hechos tienen su impacto en la pobre evidencia que se puede rescatar y, en consecuencia, en la precaria situación en que se encuentran los estudiosos para poder hacer afirmaciones de peso.

\section{Acrecentamiento del poder de las autoridades locales}

En el año 2000, México recibió la alternancia con un sistema electoral con autoridades fuertes, pero teniendo todavía grandes pendientes en derechos civiles y sociales. A poco más de una década de ese momento, los fenómenos derivados del pluralismo y de la alternancia en los gobiernos locales no son alentadores. El poder de las autoridades locales ha crecido sin arbitrio y al mismo tiempo han renacido antiguos poderes informales. Estas dos consecuencias, tal y como se vienen presentando, complican la empresa de una medición real de la calidad de la democracia a nivel local en México.

El acrecentamiento de poder de las autoridades locales fue uno de tantos cambios que experimentó el país al asumir la presidencia de la República un partido distinto al Revolucionario Institucional (PRI), el cual se había sostenido en el mando del ejecutivo federal por más de setenta años. Este hecho concitó a los gobiernos estatales, principalmente del PRI y del Partido de la Revolución Democrática (PRD), 
a la creación de la Conferencia Nacional de Gobernadores (Conago). ${ }^{24}$ Dicho organismo presentó, como intensión inicial, los compromisos que se asumirían con el sistema federal y los asuntos que los llevarían a ponerse de acuerdo en temas presupuestarios; sin embargo, también se aceptó que se creaba para dar prisa a la transición y producir equilibrios políticos (Hernández, 2008). A la postre, la Conago se volvió una instancia de presión hacia el gobierno federal y con ello los gobiernos estatales ganaron independencia y autonomía.

Así fue que los gobiernos estatales comenzaron a plantar cara al ejecutivo federal cuando no recibían el trato deseado. Algo raramente visto en el periodo del PRI-gobierno, donde el ejecutivo federal tenía, gracias a las "facultades metaconstitucionales", ${ }^{25}$ la atribución de nombrar a los gobernadores (Carpizo, 1984). En este sentido, resultaba obvio que los gobernadores eran agradecidos con el presidente y cumplían las reglas no escritas de la política mexicana. ${ }^{26}$ Pero al perder la presidencia el PRI, los gobernadores priistas encontraron motivos para comenzar a actuar por su cuenta, ya sin la obligación partidista de obedecer al presidente, ni de rendir cuentas políticas a nadie. Esto además del consabido acrecentamiento de su poder en el estado gobernado.

Tal debilitamiento del presidencialismo y tal fortalecimiento de los gobiernos estatales ha traído no muy buenas experiencias, en donde ciertos gobernadores han actuado como se caracteriza a las democracias delegativas (O’Donnell, 1994). En otras palabras, la falta de un correcto funcionamiento institucional que acote el poder de los

24. Se crea el 13 de julio de 2002 en Cancún, Quintana Roo.

25. El término facultades metaconstitucionales lo acuña Jorge Carpizo (1984) para hacer referencia a los poderes del presidente para nombrar a su sucesor $y$ a los gobernadores al ser el máximo líder y representante del Partido Revolucionario Institucional.

26. Véase Hurtado (2002, pp. 299-304). 
Calidad de la democracia en gobiernos locales: problemas y perspectivas en México

gobernadores ha permitido ver ejecutivos de los gobiernos locales actuando como si el estado fuera parte de su feudo; produciendo momentos de retroceso político en la vida de los estados que parecían ya olvidados (Hernández, 2008).

Sin duda alguna, lo que ocurre en los gobiernos locales empata con el trabajo de Morlino (2007) respecto a la relevancia de las tradiciones autoritarias para explicar la calidad democrática, ya que, como nos lo hace saber, tres son los factores que pesan en la calidad de la democracia cuando se trata de autoritarismos: a) la duración del régimen autoritario anterior, b) la innovación producida por ese régimen y c) la modalidad de transición desde el autoritarismo (Morlino, 2007, p. 13). ${ }^{27} \mathrm{Al}$ seguir estas pautas para los gobiernos locales la respuesta en el análisis empírico es de lamentar. Como es sabido, la duración del régimen autoritario anterior en los gobiernos locales se encuentra alrededor de los setenta años y solo en el caso de Baja California se está en los sesenta años. En cuanto a la innovación producida por ese régimen, el autoritario, ocurre que fue total, pues setenta años dan para eso y más. Ahora, en lo concerniente al tipo de transición, como quedó anotado en el apartado inicial, en México fue de una alta peculiaridad. Si bien fue una transición continua, pues no hubo ruptura de ningún tipo, tampoco se crearon los pactos de la clase política ni se sentaron las bases del entendi-

27. Textualmente Morlino anota: "Con innovación producida por el régimen autoritario, hay que entender el grado de transformación y de institucionalización de las reglas, de los modelos, de las relaciones y de las normas, a menudo simbolizadas por una nueva constitución, por la creación de nuevas instituciones, pero también por el grado de reforzamiento o debilitamiento de específicos intereses organizados o identidades [...], Con la modalidad de transición, nos referimos a los modos en que la transición de un gobierno autoritario haya privilegiado actores al poder y/o retadores; haya alterado (o mantenido intactas) reglas y procedimientos institucionales autoritarios; haya influenciado los llamados de las elites políticas a su electorado [...], y/o haya sido caracterizado por un cierto grado de violencia que haya hecho más probable la discontinuidad. La duración es el arco temporal durante el cual el régimen autoritario ha estado vigente" (Morlino, 2007, p. 13). 
miento de una transición y, por supuesto, no se generaron los cambios constitucionales e institucionales que impidan un retroceso al autoritarismo. Esto es, el autoritarismo no fue desterrado por completo y continúa ejerciéndose en los gobiernos locales. ${ }^{28}$ En resumen, el gobierno de la ley y la rendición de cuentas son figuras que existen y medianamente se conocen, pero no son pocos los lugares en donde están cooptadas por las autoridades locales.

\section{Resurgimiento y fortalecimiento de poderes fácticos locales}

Decíamos al inicio del apartado previo que la alternancia trajo fenómenos como el crecimiento del poder de las autoridades locales, y que muy ligado a ello, el resurgimiento y fortalecimiento de poderes fácticos locales. Pues bien, ahora nos detenemos en este último para abundar en los problemas existentes en la medición de la calidad de la democracia.

Cuando los gobiernos locales adquieren relevancia por la autonomía que han alcanzado y ganan conciencia del poder que pueden ejercer, nace, evidentemente, un interés propio por hacerse de ese poder. Ante este escenario, antiguos poderes fácticos resurgen y no encuentran límites para sus ambiciones. Se presentan, por lo tanto, altas posibilidades de violaciones a la ley sin castigo; es decir, impunidad.

El resurgimiento de antiguos líderes y caciques en los gobiernos locales hace peligrar el avance democrático, porque al fortalecerse las autoridades locales, los grupos fácticos no encuentran más interlocución para sus intereses que aquella que encarna el ejecutivo local. De tal manera que los favores, los acuerdos y las prebendas entre los grupos 
Calidad de la democracia en gobiernos locales: problemas y perspectivas en México

fácticos y la autoridad local se vuelven de uso corriente, llevando consigo una clara transformación de la vida política.

\section{Conclusiones}

Los gobiernos locales tienen sus propios problemas al ser estudiados bajo la óptica de la calidad de la democracia, como es el peso del contexto, y además son herederos de otros cuantos, como son los problemas teóricos, metodológicos y conceptuales que se derivan directamente de los estudios a nivel nacional. Así pues, las grandes discusiones que todavía plantea el estudio de la calidad de la democracia, sumadas a nuevos desafíos, hacen que la aplicación de este a los gobiernos locales se encuentre cargada de incertidumbre.

Un problema que se presenta reiteradamente en la ciencia política es la conceptualización. Los estudios sobre la calidad de la democracia también lo han padecido, y es así que todavía se discute cuál es el concepto de democracia que se maneja para, a partir de ahí, construir las dimensiones que se ajusten al estudio de su calidad. Este problema se suele zanjar incorporando apartados sobre la conceptualización utilizada; algo que consideramos más que correcto. Sin embargo, esto abre espacio para que existan tantas dimensiones de calidad de la democracia como trabajos que se ocupen de ella.

Así las cosas, el intento de medir la calidad de la democracia se hace agua muchas veces por la falta de firmeza en la construcción de dimensiones claras y por la variada y múltiple manera de hacerlo. No obstante, se debe reconocer que ya se ha establecido un marco medianamente común. Como aquí se sugiere, una primera aproximación que pudiera resultar útil para el estudio de la calidad de la democracia en los gobiernos locales incluye tres de las cinco dimensiones que propone Morlino: gobierno de la ley o Estado de derecho, rendición de cuentas y reciprocidad. 
Al hilo de lo anterior, otro problema que se deriva del propio ejercicio de la conceptualización es el de los indicadores que usados en los estudios de calidad de la democracia. La utilización de diversos índices, obtenidos a partir de metodologías distintas, que son cruzados entre sí para producir unos resultados aparentes bajo una misma óptica, vuelve los resultados inciertos. En el caso concreto de los estudios de la calidad de la democracia en los gobiernos locales nos encontramos ante la dificultad de contar con datos fiables a nivel local, ya que son fácilmente manipulables o simplemente inexistentes. Por ello, es preferible la producción de índices sencillos, pero confiables y claros, y metodológicamente correctos, a la realización de investigación basada en inferencias y evidencias empíricas poco sustentadas.

Aparte de estos problemas teóricos, conceptuales y metodológicos, el estudio de la calidad de la democracia en los gobiernos locales exige prestar especial atención al contexto. Esto debido a que los gobiernos locales no son la reproducción de lo que ocurre en el ámbito nacional, sino que suelen responder a inercias propias: por ejemplo, la baja institucionalización, el acrecentamiento del poder de las autoridades locales y el fortalecimiento de los poderes fácticos locales, en el caso mexicano.

Es así que la heterogénea realidad de los gobiernos locales nos obliga a decantarnos por metodologías mixtas que consideren enfoques cualitativos, a partir de análisis de corte interpretativo, sin dejar de lado los enfoques cuantitativos. En este sentido, se requiere replantear el tipo de indicadores a utilizar en este tipo de estudios y adaptarlos a lo que la realidad local exige.

Finalmente, nos resta reconocer que el estudio de la calidad de la democracia en los gobiernos locales es una aventura temprana para lo que la literatura sobre el tema exige. Es por ello que, al menos en los primeros pasos, estos 
Calidad de la democracia en gobiernos locales: problemas y perspectivas en México

estudios deben prever alcances modestos, ya que vale más contar con poca información, pero veraz y verificable, que con demasiados datos dudosos que den lugar a respuestas inciertas.

Fechas de recepción: 10 de marzo de 2014

Fechas de aceptación: 15 de octubre de 2014

Alcántara, Manuel (ed.) (2006). Políticos y política en América Latina. Madrid: Siglo XXI / Fundación Carolina.

Bibliografía (2008). "Luces y sombras de la calidad de la democracia en América Latina." Revista de Derecho Electoral del Tribunal Supremo de Elecciones, 6, I-I5.

Altman, D., y Aníbal Pérez-Liñán (2002). "Assessing the Quality of Democracy: Freedom, Competitiveness and Participation in Eigtheen Latin American Countries", Democratization, 2, 85-100.

Cansino, César, e Israel Covarrubias (coords.) (2007). Por una democracia de calidad. México después de la transición. México: CEPCOM / Educación y Cultura.

Carpizo, Jorge. 1978. El presidencialismo mexicano. México: Siglo XXI.

Diamond, Larry, y Leonardo Morlino (2004). “The Quality of Democracy.An Overview”, Journal of Democracy, I5, 20-3I.

Emmerich, Gustavo Ernesto (2009).“Informe sobre la democracia en México”, Araucaria, I I, I86-225.

Gervasoni, Carlos H. (2005). “Poliarquías a nivel sub-nacional. Aspectos conceptuales y normativos en el contexto de las democracias federales", Colección, I6, 83-I 22.

Hernández Rodríguez, Rogelio (2008). El centro dividido: la nueva autonomía de los gobernadores. México: El Colegio de México. 
Hurtado, Javier (200I). Sistema presidencial mexicano: evolución y perspectivas. México: Fondo de Cultura Económica / Universidad de Guadalajara.

Levine, Daniel H., y José Enrique Molina (2007). “La calidad de la democracia en América Latina: una visión comparada", América Latina Hoy, 45, 17-46.

Maravall, José María (2003). El control de los políticos. Madrid: Taurus.

Meyer, Lorenzo (20I3). Nuestra tragedia persistente. La democracia autoritaria en México. México: Debate.

Morlino, Leonardo (2005a). "Calidad de la democracia. Notas para su discusión”, Metapolítica, 9, 37-54.

(2005b). Democracia y Democratizaciones. México: CEPCOM.

- (2007). “Explicar la calidad democrática: ¿qué tan relevantes son las tradiciones autoritarias?", Revista de Ciencia Política, 27, 3-22.

Munck, Gerardo L., y Jay Verkuilen (2002). "Conceptualizando y midiendo la democracia: Una evaluación de índices alternativos", Política y Gobierno, IX, 403-44I.

O'Donnell, G (1994). “Delegative Democracy”, Journal of Democracy, 5, 55-69.

(1999). "Horizontal Accountability and $\mathrm{New}$ Polyarchies", en A. Schedler et al. (eds.), The self-Restraining State: Power and Accountability en New Democracies (pp. 29-52). Boulder / London: Lynne Rienner Publishers. (1997). Contrapuntos: ensayos escogidos sobre autoritarismo y democratización. México: Paidos.

Powell Jr., G. Bingham (2007). "Calidad de la democracia: reciprocidad y responsabilidad”, en César Cansino, e Israel Covarrubias (coords.), Por una democracia de calidad. México después de la transición (pp.97-I II). México: CEPCOM / Educación y Cultura.

Sartori, Giovanni (1984). La Política. Lógica y métodos en las ciencias sociales. México: Fondo de Cultura Económica. 
Calidad de la democracia en gobiernos locales: problemas y perspectivas en México

Schedler, Andreas (2004). Qué es la rendición de cuentas. Bibliografía México: Instituto Federal de Acceso a la Información Pública.

Schmitter, Philippe C. (2007). "Calidad de la democracia: las virtudes ambiguas de la rendición de cuentas", en César Cansino, e Israel Covarrubias (coords.), Por una democracia de calidad. México después de la transición (pp. 75-96). México: CEPCOM / Educación y Cultura.

Whitehead, Laurence (1996). “Una transición difícil de alcanzar: la lenta desaparición del gobierno de partido dominante en México", Política y Gobierno, III: 31-59.

Woldenberg, José (2002). La construcción de la democracia. México: Plaza y Janés.

(2006). Los desafios del presente mexicano. México:Taurus. 